\title{
ADHS und motorische Auffälligkeiten treten häufig gemeinsam auf
}

Die Aufmerksamkeitsdefizit-/Hyperaktivitätsstörung (ADHS) ist häufig mit Problemen in der Motorik begleitet. Die Autoren einer Studie untersuchten den Zusammenhang zwischen diesen beiden klinischen Merkmalen.

$\mathrm{H}$ olländische Wissenschaftler nahmen 275 Kinder mit ADHS und ihre Geschwister sowie 146 Kontrollkinder in eine Studie auf. Die Beurteilung der Motorik erfolgte mithilfe von Fragebögen (GMO und DCD-Q), die von Lehrern und Eltern ausgefüllt wurden.

Es zeigte sich, dass die Kinder mit ADHS signifikant häufiger Störungen in ihrer Grob- und Feinmotorik hatten als ihre Geschwister. Diese wiederum schnitten signifikant schlechter ab als die Kontrollkinder. Vor allem die Feinmotorik war bei den Kindern mit ADHS betroffen. Die Autoren schließen aus diesen Ergebnissen, dass die Kombination ADHS plus motorische Störungen einen genetisch determinierten Subtyp der ADHS darstellt.

Kommentar: Bedauerlich ist, dass es in der Studie keine „objektivere“ Beurteilung der motorischen Störungen, z. B.

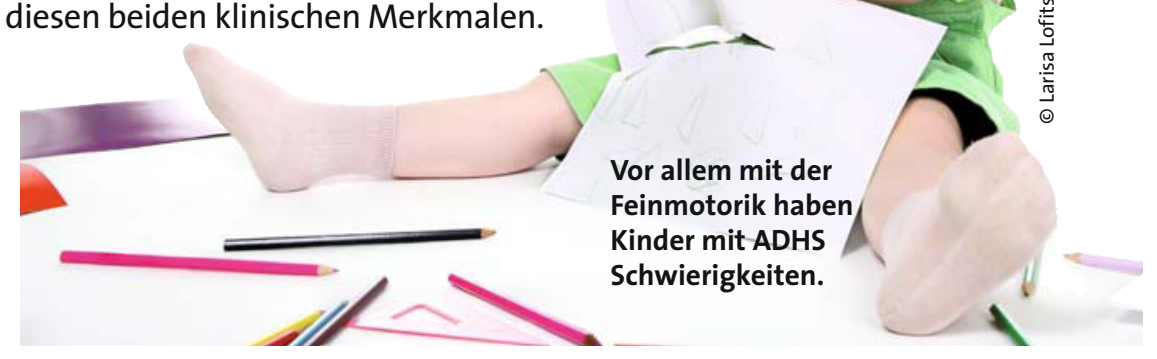

durch einen Neuropädiater mithilfe von motorischen Tests (MOT etc.) gab. Denn die Aussagen der Lehrer und der Eltern variieren doch erheblich. Die Ergebnisse bestätigen die Untersuchungen von Christopher Gillberg [Arch Dis Child 2003; 88: 904-10], der den Begriff DAMP („deficits in attention motor control and perception") prägte. Bereits Martin et al. stellten anhand von Zwillingsuntersuchungen die Hypothese auf, dass eine gemeinsame genetisch bedingte Basis der beiden Störungen besteht [Hum Mov Sci 2006; 25: 110-24]. Dies ist auch die Hypothese der Autoren der vor- liegenden Studie. Interessant wäre, ob es gelingt, die ADHS, die mit motorischen Störungen einhergeht, klinisch mehr zu differenzieren $-z$. B. herauszufinden, ob es sich um ADS oder ADHS handelt. Des Weiteren fehlen Angaben darüber, ob es Unterschiede zwischen Jungen und Mädchen gab, und ob weitere Probleme wie Sprachstörungen gehäuft auftraten.

Dr. Kirsten Stollhoff

Fliers $\mathrm{E}$ et al. ADHD and poor motor performance from family genetic perspective. J Am Acad Child Adolesc Psychiatry 2009; 48: 25-34

\section{Ist eine laborgesteuerte Therapie des offenen Ductus Botalli in Sicht?}

In einer US-amerikanischen Studie sollte untersucht werden, ob sich durch die Messung der Serumkonzentration von „brain natriuretic peptide“ (BNP), auch „B-type natriuretic peptide“ genannt, Indomethacin-Gaben einsparen lassen.

$\mathrm{D}$ ie Wissenschaftler therapierten zum einen 30 Frühgeborene mit persistierendem Ductus arteriosus (PDA) konventionell mit Indomethacin (ein Kurs entsprach drei Gaben im Abstand von $12 \mathrm{~h})$. Bei weiteren 30 wurde vor der geplanten Indomethacin-Gabe eine BNP-Bestimmung durchgeführt und die Therapie beendet, wenn das BNP unter $100 \mathrm{pg} / \mathrm{ml} \mathrm{lag}$.

Die Ausgangswerte für BNP lagen im Schnitt bei 500 bzw. 542 pg/ml (Kontrollgruppe bzw. BNP-Gruppe), nach der Therapie bei 126 bzw. 85 pg/ml. Die
Frühgeborenen in der BNP-gesteuerten Gruppe erhielten insgesamt 70 Gaben Indomethacin, in der Kontrollgruppe 88 Gaben, was eine signifikante Reduktion darstellte. Es gab keine Unterschiede zwischen den Gruppen im Bezug auf die Verschlussrate nach dem ersten Kurs, Indomethacin-Gaben nach dem ersten Kurs, Häufigkeit der PDA-Ligatur, Darmperforationen, bronchopulmonale Dysplasie und die Serumkreatininkonzentration.

Kommentar: BNP wurde zuerst im Gehirn von Schweinen nachgewiesen (daher „brain-type“). Später wurde entdeckt, dass es vor allem von den Muskelzellen der Herzkammern produziert wird, wenn die Dehnung der Wände zunimmt (beim PDA durch linksventrikuläre Volumenüberlastung). Deshalb kann es zur Schweregradeinschätzung einer Herzinsuffizienz genutzt werden. Es handelt sich um einen interessanten Ansatz, um den Therapieerfolg zu kontrollieren und womöglich überflüssige Gaben zu verhindern. Die Indomethacingaben konnten durch das Vorgehen zwar reduziert werden, die Nebenwirkungen jedoch nicht - insofern ist ein Routineeinsatz dieser Methode nicht gerechtfertigt.

Dr. Levente Bejo

Attridge JT et al. B-type natriuretic peptide concentrations to guide treatment of patent ductus arteriosus. Arch Dis Child Fetal Neonatal Ed 2009; 94: F178-82 